\title{
ANALYZING NEAR WATER SURFACE PENETRATION IN LASER BATHYMETRY - A CASE STUDY AT THE RIVER PIELACH
}

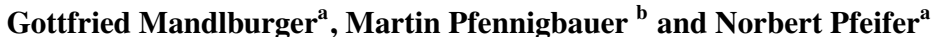 \\ ${ }^{a}$ Vienna University of Technology, Department of Geodesy and Geoinformation \\ Gusshausstrasse 27-29/E120.7, A-1040, Vienna, Austria, E-mail: gottfried.mandlburger@geo.tuwien.ac.at

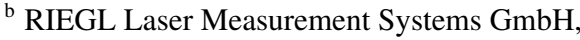 \\ Riedenburgstr. 48, A-3580 Horn, Austria
}

Commission III/2

KEY WORDS: Airborne laser bathymetry, LIDAR bathymetry, green laser wavelength, water penetration, water surface models

\begin{abstract}
:
Recent developments in sensor technology yielded a major progress in airborne laser bathymetry for capturing shallow water bodies. Modern topo-bathymetric small foot print laser scanners do no longer use the primary near infrared (NIR) signal $(\lambda=1064 \mathrm{~nm})$ but only emit and receive the frequency doubled green signal $(\lambda=532 \mathrm{~nm})$. For calculating correct water depths accurate knowledge of the water surface (air-water-interface) is mandatory for obtaining accurate spot positions and water depths. Due to the ability of the green signal to penetrate water the first reflections do not exactly represent the water surface but, depending on environmental parameters like turbidity, a certain penetration into the water column can be observed. This raises the question if it is even feasible to determine correct water level heights from the green laser echoes only.

In this article, therefore, the near water surface penetration properties of the green laser signal are analyzed based on a test flight of the River Pielach (Austria) carried out with Riegl's VQ-820-G (532 nm) and VQ-580 (1064 nm) scanners mounted on the same airborne platform. It is shown that within the study area the mean penetration into the water column is in the range of $10-25 \mathrm{~cm}$ compared to the NIR signal as reference. However, as the upper hull of the green water surface echoes coincides with the NIR signal with cm-precision, it is still possible to derive water surface models from the green laser echoes only via statistical analysis of aggregated neighboring echoes and robustly keep the underestimation of the water level below $6 \mathrm{~cm}$. This especially holds for still and stationary flowing water bodies.
\end{abstract}

\section{INTRODUCTION}

Airborne laser bathymetry (ALB), also referred to as airborne laser hydrography (ALH) or LiDAR bathymetry, is a technique for measuring the depths of relatively shallow, coastal waters from the air using a scanning, pulsed laser beam (Guenther et al., 2000). In the recent past, progress in sensor technology enabled an increase of the effective bathymetric measurement rate to up to $200 \mathrm{kHz}$ (Mandlburger et al., 2011) resulting in a sounding density of typically beyond 10 points $/ \mathrm{m}^{2}$. Thus, ALB is no longer restricted to large coastal areas but can also be applied to fluvial topography and other smaller inland waters like shallow lakes, ponds, rivers, and creeks (Pfennigbauer et al., 2011), (Steinbacher and Pfennigbauer, 2010).

ALB is a two-media measurement process (Laroque and West, 1999). A short green laser pulse $(\lambda=532 \mathrm{~nm})$ is emitted from an airborne platform, travels through the atmosphere, and hits the water surface where it gets refracted. Within the water column the laser beam propagates with reduced velocity, is scattered at water and sediment particles, a part of the signal is reflected from the bottom of the water body, and, after the return trip, the full waveform of the backscattered echo signal is detected at the receiver. Beam refraction as a consequence of the different propagation speeds in air and water are described by Snell's law. (c.f. Fig. 1):

$$
\frac{\sin \alpha_{\text {air }}}{\sin \alpha_{\text {water }}}=\frac{c_{\text {air }}}{c_{\text {water }}}=\frac{n_{\text {water }}}{n_{\text {air }}}
$$

$n_{\text {air }}$ and $n_{\text {water }}$ denote the refractive indices in air and water at the respective wavelength and $c_{a i r}$ and $c_{\text {water }}$ the corresponding group velocities. $\alpha_{\text {air }}$ is the incidence angle of the laser beam w.r.t. the normal vector of the water surface (i.e. the zenith direction in general) and $\alpha_{\text {water }}$ the refracted angle in the optical thicker medium water. The refractive index $n_{\text {water }}$ of clear water at $20^{\circ} \mathrm{C}$ is 1.33 , thus, the speed of light is ca. one third higher in air compared to water. The $3 \mathrm{D}$ position $\mathbf{x}$ of a water bottom point is calculated by:

$$
\mathbf{x}=\mathbf{o}+\mathbf{r}_{\text {air }} \frac{\Delta t_{\text {air }} c_{\text {air }}}{2}+\mathbf{r}_{\text {water }} \frac{\Delta t_{\text {water }} c_{\text {water }}}{2}
$$

where $\Delta t_{\text {air }}$ and $\Delta t_{\text {water }}$ correspond to the round trip time of the laser beam in air and water, $\mathbf{r}_{\mathbf{a i r}}$ and $\mathbf{r}_{\mathbf{w a t e r}}$ are the corresponding beam direction unit vectors and $\mathbf{o}$ is the scanner origin. From Equations 1 and 2 it becomes clear that for obtaining correct 3D positions of bathymetric points knowledge of the water level height at the intersection of the laser beam and the water surface is a precondition. An error in the height estimation of the water surface directly causes an error of the derived water depths and $3 \mathrm{D}$ spot positions at the water bottom.

In the ideal case each laser pulse would return an echo from the water surface and bottom, but, in practice, this is not always the case. Instead, all potential combinations of return echoes are observed: i.e. water surface echo only, water bottom echo only, both echoes, or no echo at all. This especially applies for topobathymetric sensors using very short laser pulses in the ns-range and low beam divergence of ca. 1 mrad resulting in a footprint size of less than $1 \mathrm{~m}$. The primary near infrared (NIR) radiation $(\lambda=1064 \mathrm{~nm})$ was used by pure bathymetric systems in the past (Guenther et al., 1994). On the one hand, the NIR signal does not penetrate into the water column and, therefore, delivers reliable 


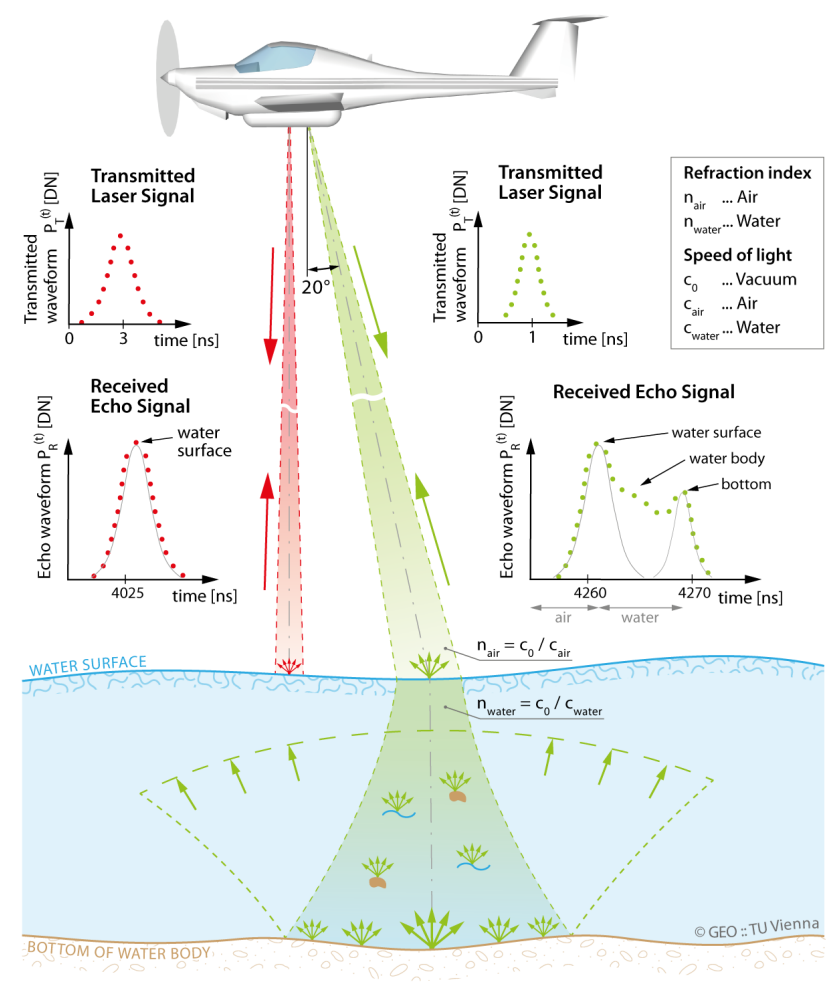

Figure 1: Topographic (NIR) and topo-bathymetric (green) laser scanners mounted on the same airborne platform; left: reflection of NIR signal at water surface; right: principle of airborne laser bathymetry (refraction of laser beam at water surface, echoes from near water surface, water column, and water bottom)

water surface information, but on the other hand, even for NIR signal it is not guaranteed that enough energy is scattered back to the receiver in order to detect a water surface echo for each pulse. The strong absorption of NIR radiation at water and the slanting beam angle of ca. $20^{\circ}$ employed in laser bathymetry (Guenther, 1985) together with the high amount of directional reflection of smooth water surfaces are the main sources for drop outs. Laser echo drop outs have even been used for the delineation of water bodies based on NIR signal (Höfle et al., 2009).

The point of reflection of the green pulse is not well known but penetration into the top layer of the water column is possible. It is, thus, not guaranteed that the first echo is on the air-waterinterface. Furthermore, as detailed before, not all pulses generate echoes on or near the water surface and on the bottom of the water body. Therefore, the approach of reconstructing the air-water-interface from suitably selected neighboring echoes is investigated. This would allow to reconstruct $\mathbf{r}_{\text {air }}$ and consequently $\mathbf{r}_{\text {water }}$ for all echoes originating from the water column or bottom. The research questions for this paper are therefore: Is it possible to derive the water surface model with sufficient accuracy for range and refraction correction based on the green signal only? Furthermore, can geometrical properties of the near water surface point cloud be linked to influencing environmental parameters like turbidity?

The main interest is on analyzing and understanding the near water surface penetration behaviour of the green signal. The whole topic is addressed empirically by analyzing the data of a test flight at the River Pielach with a topographic and topobathymetric scanner (Riegl VQ-580 and VQ-820-G) mounted on the same platform.

The remainder of the article is structured as follows: In Section
2 the study area and the setup of the flight experiment are introduced. Section 3 details the employed statistical analysis methods and in Section 4 results obtained from analyzing the flight data are discussed. Conclusions are drawn in Section 5 together with an outlook to pending research work.

\section{STUDY AREA}

The study area is located at the lower course of the River Pielach between Loosdorf and Melk (c.f. Fig. 2). The River Pielach is a gravel river situated in the Lower Austrian Alpine foreland (Melcher and Schmutz, 2010). After a $70 \mathrm{~km}$ run with a source-to-outlet height difference of $775 \mathrm{~m}$ the River Pielach discharges into the River Danube near Melk. The total catchment area adds up to $950 \mathrm{~km}^{2}$. From an ecological point of view the River Pielach is an important retreat area for several fish and bird habitats (huchen, river kingfisher ...). This especially applies for the study area Neubacher Au (N48 13 ' / E15 23 ', c.f. Fig. 2b-e). Being a Natura2000 conservation area, space for a meandering flow is allowed within the alluvial forest and the adjacent floodplain. Parts of the floodplain to the north of the river have been anthropogenically transformed in the recent decades by quarrying the gravel deposits. As a result, the floodplain area is now dominated by 14 groundwater ponds used for fishing and recreation (c.f. 2b). The ponds with their near perfectly horizontal water surface constitute ideal test areas for studying the penetration behavior of the green laser signal. Additionally, some nearby river sections have been chosen to include running water reaches as well (c.f. Fig. 2c).

The test flight took place on May, 242013 and was carried out under leaf-on and low flow conditions. Two scanners (NIR: Riegl VQ-580, $\lambda=1064 \mathrm{~nm}$, pulse repetition rate (prr) $=200 \mathrm{kHz}$, effective measurement rate $(\mathrm{emr})=100 \mathrm{kHz}$; green: Riegl VQ-820$\mathrm{G}, \lambda=532 \mathrm{~nm}, \mathrm{prr}=520 \mathrm{kHz}, \mathrm{emr}=200 \mathrm{kHz}$ ) were mounted on the same platform located in the nose pod of a Diamond DA42 light aircraft flown in an altitude of $600 \mathrm{~m}$ above ground at a speed of 110 knots. A schematic diagram of the scanner configuration is illustrated in Fig. 1. The regular flight line distance was $240 \mathrm{~m}$ (Line01-Line04, c.f. Fig. 2c) with an additional flight line between the two northernmost lines (Line011). The swath width was $710 \mathrm{~m}$ (VQ-580, scan angle: $\pm 30^{\circ}$ ) and $480 \mathrm{~m}$, respectively (VQ-820-G, scan angle: $\pm 21^{\circ}$ ). Both scanners perform online waveform processing resulting in additional attributes (amplitude, reflectance, pulse shape deviation) per echo (Riegl LMS, 2013).

After calculating the raw 3D point cloud by combining the scanner and trajectory data a rigorous strip adjustment was carried out for the entire flight block (including cross strips) with the RiProcess software. The geometric fitting precision was verified by an independent quality control cycle using the software OPALS (Mandlburger et al., 2009), (Ressl et al., 2009). In the strip overlap areas the vertical discrepancies were calculated for both sensors separately as well as between the NIR and green flight block. All tested combinations featured a $\sigma_{m a d}$ (i.e. median of absolute differences) in the range of $2 \mathrm{~cm}$ which is below the ranging accuracy of both sensors of $2.5 \mathrm{~cm}$. The flight data can, therefore, considered to be well suited for a comparison of NIR and green data.

\section{METHODS}

In a preprocessing step the water land boundary was derived for all ponds and the river, the test areas were delineated, and, finally, the water surface echoes were extracted for each test area (ponds: P01-14, river sections: R01-05) separately for NIR and green. The green echoes were selected within a tolerance band of $5 \mathrm{~cm}$ 
ISPRS Annals of the Photogrammetry, Remote Sensing and Spatial Information Sciences, Volume II-5/W2, 2013 ISPRS Workshop Laser Scanning 2013, 11 - 13 November 2013, Antalya, Turkey
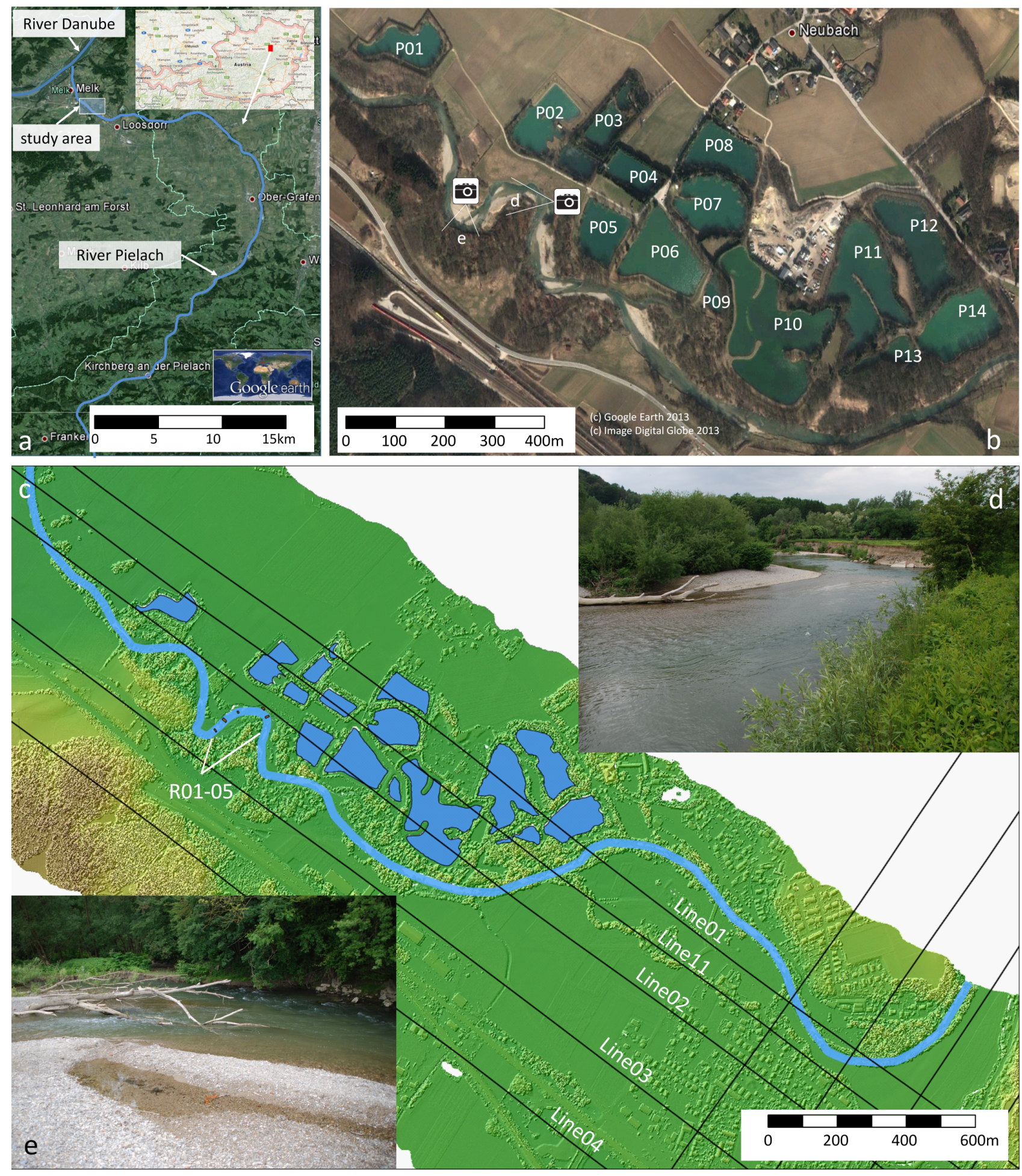

Figure 2: Study area Neubacher Au, River Pielach, Lower Austria; (a) Overview map, River Pielach and location of study area; (b) Digital orthophoto of Neubacher Au including labeled groundwater ponds used as actual test areas; (c) Digital surface model of relevant flight block section, superposition of hill shading and z-coloring overlaid with additional vector data (flight strips, pond and river test area outlines, coarse river outline; (d) and (e) terrestrial photos of meandering river section taken on the flight day May 24, 2013 


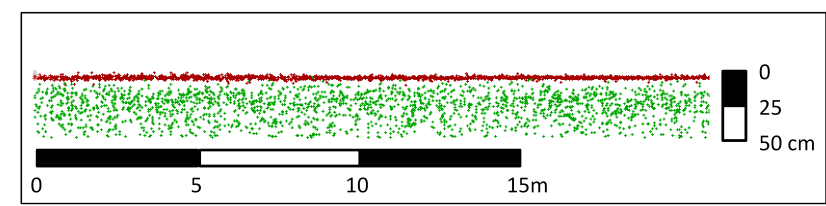

Figure 3: Vertical section of the near water surface point cloud (red: VQ-580, green: VQ-820-G)

above to $50 \mathrm{~cm}$ below the average water level. The lower bound was chosen because in all but the most turbid waters the point density of near water surface echoes has almost entirely subsided at that depth. For each of the 14 ponds and 5 river sections the NIR and green point clouds are now available separately for detailed analysis using the methods described in this section.

First, for the NIR (VQ-580) data of each area the following products are derived: (i) histograms featuring the z-distribution including standard statistical parameters (min, mean, median, max, $\sigma, \sigma_{m a d}$, r.m.s.), (ii) a point density map (cell size: $2 \mathrm{~m}$ ), (iii) a water surface model in regular grid structure (post spacing: $0.5 \mathrm{~m}$ ) via moving average ${ }^{1}$ interpolation based on the 8 nearest neighbors within a maximum search radius of $2.5 \mathrm{~m}$, (iv) visualizations of the above model (shading, z-coloring, mean interpolation error), and (v) a difference model w.r.t. the overall mean elevation.

For the green (VQ-820-G) data, the following analysis steps are carried out: (i) the range and refraction correction according to equations 1 and 2 is applied to the raw laser echoes based on the mean elevation of all NIR data points, (ii) a point density map and digital water surface model (including visualizations) are derived as described above, (iii) raster models representing the 50/75/90/95/99/100\% quantile are calculated for different resolutions $(0.5 / 1 / 2 / 5 / 10 \mathrm{~m}$, (iv) for each of the above raster models the difference w.r.t. the NIR-mean as reference are calculated, and (v) the deviations are visualized and statistically analyzed.

\section{RESULTS AND DISCUSSION}

A first visual inspection of the data led to the assumption, that the available NIR echoes describe the horizontal water surface of the ponds and local river sections with a precision in the range of the ranging accuracy as stated by the manufacturer (c.f. Fig. 3). Furthermore, although the green water surface echoes more or less penetrate into the water column within a band of ca. $50 \mathrm{~cm}$ the upper hull of the green water surface echoes seems to approximate the surface spanned by the NIR points quite well. The scope of this section is to present the results of the analysis described in the previous section and to verify the above assumptions.

Fig. 4 shows the histograms of areas P06 and P14 featuring the z-distribution of the NIR and green water surface echoes. Tab. 1 contains corresponding statistical parameters for selected representative test areas. Fig. 4 and Tab. 1 clearly show that the dispersion of the NIR echoes expressed as $\sigma_{\text {mad }}$ is generally in the range of $2 \mathrm{~cm}$ and much less compared to green surface returns (9-14 cm for the selected areas). The NIR mean values are strictly higher which confirms the penetration of the green signal into the water column. In contrast to the NIR data, the green echoes show a noticeable difference between the mean and the median. The latter is always higher which means that the echo density is decreasing with increasing distance from the water surface.

The point density is much higher for the green data compared to the NIR which verifies what already became apparent visually in

\footnotetext{
${ }^{1}$ Also termed: running average, rolling average, rolling mean, ..
}
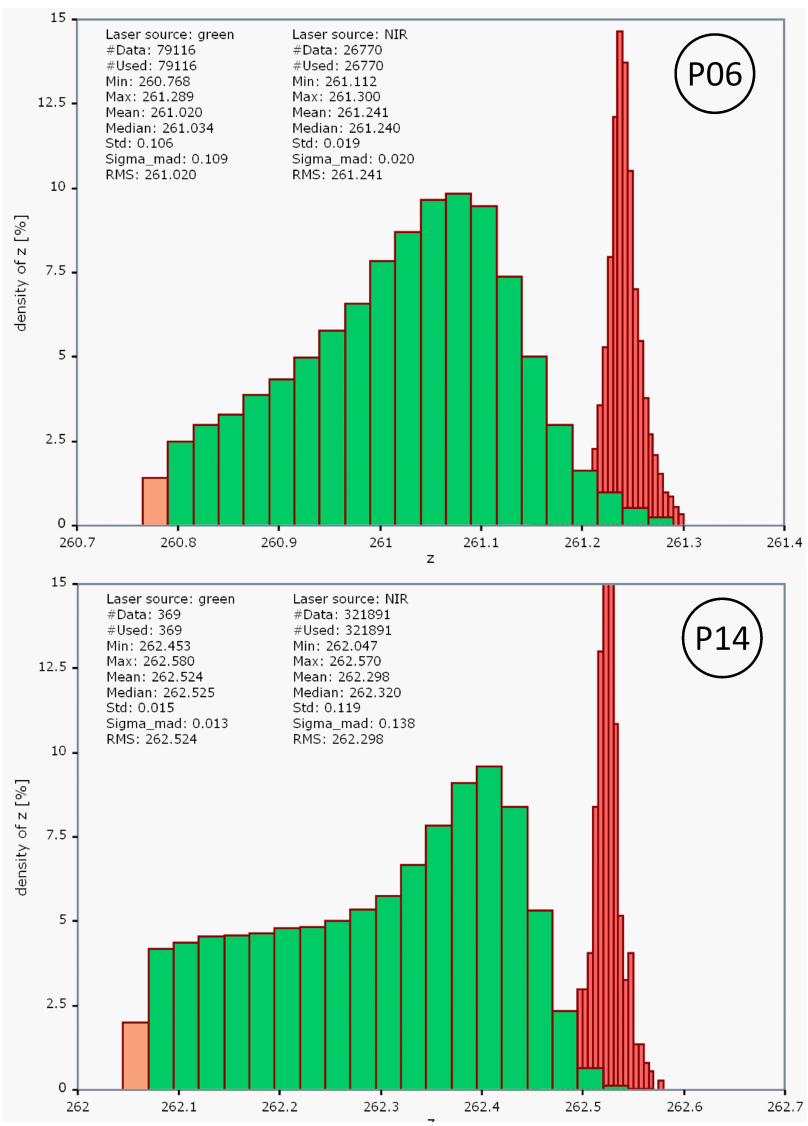

Figure 4: Histogram of NIR and green elevation data of area P06 (upper) and P14 (lower); red bars correspond to NIR signal and green bars to green signal)

Fig. 3. Whereas the variation in the NIR point density can be explained by the high incidence angle variation of the nadir looking NIR scanner, the density differences in the green signal are remarkable. First, it should be noted that the density is higher for the river sections (ca. $20 \mathrm{pts} / \mathrm{m}^{2}$ compared to the ponds which may be explained by the higher surface roughness in the meandering section of the river. Second, the high density variability among the tested ponds $\left(5-23 \mathrm{pts} / \mathrm{m}^{2}\right.$ seems implausible as one should expect a similar behavior for all standing waters. In fact, the individual ponds feature different water quality. Area P14 exhibiting the highest point density of $23 \mathrm{pts} / \mathrm{m}^{2}$ appears quite turbid in the digital orthophoto (c.f. Fig. 2b). The turbidity results in a higher level of volume backscatter in the water column which can also be observed in the histogram (flat left tail in the P14 histogram of Fig. 4). Area P10, in contrast, with a low density of $8 \mathrm{pts} / \mathrm{m}^{2}$ features relatively clear water. However, additional data (e.g. water samples) would be necessary to draw secured conclusions.

As described in Section 3 for, both, NIR and green data a $0.5 \mathrm{~m}$ water surface grid was calculated. The results for the NIR data of area P06 are presented in Fig. 5. Fig. 5a shows the deviation of the surface grid w.r.t. to the overall mean. It is striking that high deviation areas correlate to low point density (b), low target reflectance (c) and high local interpolation error (d). Poor signal quality, thus, results in a higher local height uncertainty. It should be mentioned that remaining georeferencing errors and/or small local waves may also contribute to the height differences, but as the $\sigma_{\text {mad }}$ of the discrepancies of $2 \mathrm{~cm}$ is well below the ranging accuracy of the sensor we conclude that it is justified to use a horizontal plane at the overall mean level as the water surface reference for each test area. 


\begin{tabular}{llrrrrrrrr}
\hline & wavelength & PID02 & PID04 & PID06 & PID07 & PID10 & PID14 & RID02 & RID04 \\
\hline mean $[\mathrm{m}]$ & NIR & 260.13 & 260.91 & 261.24 & 261.29 & 262.00 & 262.52 & 259.96 & 260.21 \\
$\sigma_{\text {mad }}[\mathrm{m}]$ & NIR & 0.01 & 0.02 & 0.02 & 0.02 & 0.02 & 0.01 & 0.03 & 0.02 \\
density $\left[\mathrm{pts} / \mathrm{m}^{2}\right.$ ] & NIR & 1.20 & 0.75 & 1.73 & 1.01 & 2.25 & 0.03 & 0.90 & 2.25 \\
mean $[\mathrm{m}]$ & green & 259.89 & 260.67 & 261.02 & 261.05 & 261.87 & 262.30 & 259.82 & 260.06 \\
median $[\mathrm{m}]$ & green & 259.90 & 260.68 & 261.03 & 261.06 & 261.94 & 262.32 & 259.83 & 260.06 \\
$\sigma_{\text {mad }}[\mathrm{m}]$ & green & 0.12 & 0.12 & 0.11 & 0.11 & 0.09 & 0.14 & 0.09 & 0.10 \\
density $\left[\mathrm{pts} / \mathrm{m}^{2}\right.$ ] & green & 12.83 & 8.00 & 5.12 & 7.46 & 8.16 & 22.74 & 20.55 & 19.00 \\
\hline
\end{tabular}

Table 1: Statistical analysis of z-distribution of NIR and green water surface echoes

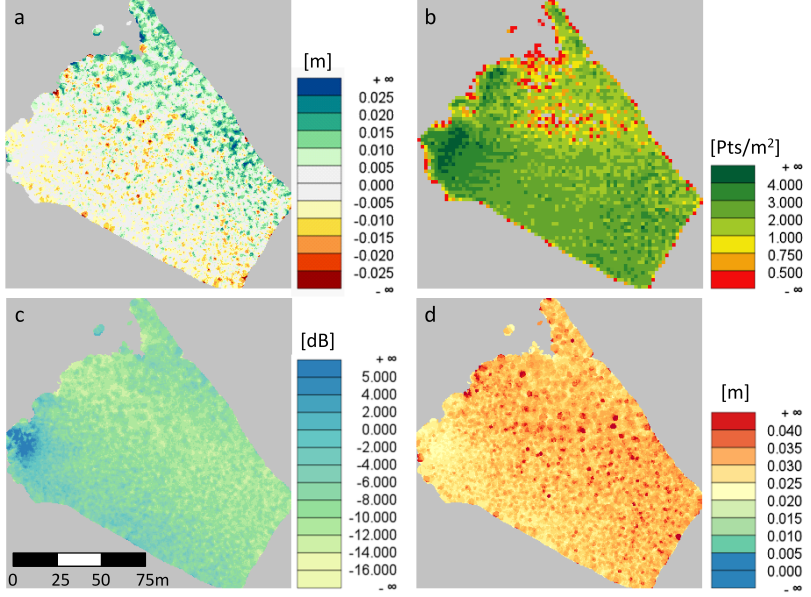

Figure 5: Digital water surface model $(0.5 \mathrm{~m}$ grid $)$ of test area P06 derived from NIR echoes; (a) height deviations [m] w.r.t. overall mean; (b) echo density map [points $/ \mathrm{m}^{2}$ ); (c) target reflectance map $[\mathrm{dB}] ;$ (d) mean interpolation error $[\mathrm{m}]$

To quantify how well the water surface derived from the green echoes only can approximate the reference height, raster models of multiple height quantiles are calculated in different resolutions. Tab. 2 summarizes the mean deviations of the different water surface raster models compared to the respective reference height for test areas P06, P14 and R02 .

It can be seen that all of median raster models (q0.5) underestimate the reference height. This measure allows a quantification of the well known near water surface penetration effect of the green signal. The q0.5 deviations are independent from the cell resolution but significantly vary among the test areas from $-13 \mathrm{~cm}$ to $-21 \mathrm{~cm}$ (overall $\mathrm{min} / \mathrm{max}$ : $-10 /-24 \mathrm{~cm}$ for R05/P07). A visual comparison to the orthophoto (Fig. 2b) allows the conclusion that the median deviation is larger for turbid water than for clear water. This especially could be verified for all river sections featuring more transparent water compared to the tested pond areas. Based on the above arguments it can be stated that the median is an inappropriate, biased estimator for the water surface height derived from green near-water surface returns only.

Whereas the median is almost independent from the cell resolution the higher quantiles show a clear dependency. Tab. 2 allows the following interpretation:. The larger the cell size and the higher the quantile the better the reference height can be approximated by the respective green-only water surface models. E.g. for test area R02, the underestimation can be reduced from $-13 \mathrm{~cm}$ to $-6 \mathrm{~cm}$ based on the $0.5 \mathrm{~m}$ raster model when using the 99\% quantile instead of the median. The $100 \%$ quantile model can even perfectly approximate the reference by aggregating the water surface echoes into $10 \mathrm{~m}$ raster cells. The same trend can be observed for P06 and P14. Test area P14 even shows an overestimation of the reference height for the $\mathrm{q} 1.0 / 10 \mathrm{~m}$ combination. It should be mentioned here, that the maximum height per cell

\begin{tabular}{rrrrrr}
\hline & & & $\mathrm{P} 06$ & & \\
& $0.5 \mathrm{~m}$ & $1.0 \mathrm{~m}$ & $2.0 \mathrm{~m}$ & $5.0 \mathrm{~m}$ & $10.0 \mathrm{~m}$ \\
\hline $\mathrm{q} 0.50$ & -0.22 & -0.22 & -0.21 & -0.21 & -0.21 \\
$\mathrm{q} 0.75$ & -0.18 & -0.17 & -0.15 & -0.15 & -0.15 \\
$\mathrm{q} 0.90$ & -0.16 & -0.14 & -0.11 & -0.10 & -0.10 \\
$\mathrm{q} 0.95$ & -0.15 & -0.13 & -0.09 & -0.08 & -0.08 \\
$\mathrm{q} 0.99$ & -0.15 & -0.12 & -0.07 & -0.04 & -0.03 \\
$\mathrm{q} 1.00$ & -0.15 & -0.12 & -0.07 & -0.02 & 0.00 \\
\hline & & & $\mathrm{P} 14$ & & \\
& $0.5 \mathrm{~m}$ & $1.0 \mathrm{~m}$ & $2.0 \mathrm{~m}$ & $5.0 \mathrm{~m}$ & $10.0 \mathrm{~m}$ \\
\hline $\mathrm{q} 0.50$ & -0.21 & -0.21 & -0.20 & -0.20 & -0.20 \\
$\mathrm{q} 0.75$ & -0.15 & -0.13 & -0.13 & -0.12 & -0.13 \\
$\mathrm{q} 0.90$ & -0.11 & -0.09 & -0.09 & -0.08 & -0.09 \\
$\mathrm{q} 0.95$ & -0.10 & -0.08 & -0.07 & -0.07 & -0.07 \\
$\mathrm{q} 0.99$ & -0.09 & -0.06 & -0.04 & -0.04 & -0.04 \\
$\mathrm{q} 1.00$ & -0.09 & -0.05 & -0.03 & -0.00 & 0.01 \\
\hline & & & $\mathrm{R} 02$ & & \\
& $0.5 \mathrm{~m}$ & $1.0 \mathrm{~m}$ & $2.0 \mathrm{~m}$ & $5.0 \mathrm{~m}$ & $10.0 \mathrm{~m}$ \\
\hline $\mathrm{q} 0.50$ & -0.13 & -0.13 & -0.13 & -0.13 & -0.13 \\
$\mathrm{q} 0.75$ & -0.10 & -0.09 & -0.09 & -0.09 & -0.09 \\
q0.90 & -0.08 & -0.06 & -0.06 & -0.05 & -0.06 \\
q0.95 & -0.07 & -0.05 & -0.05 & -0.03 & -0.05 \\
$\mathrm{q} 0.99$ & -0.06 & -0.04 & -0.03 & -0.01 & -0.03 \\
q1.00 & -0.06 & -0.03 & -0.02 & 0.01 & -0.00 \\
\hline
\end{tabular}

Table 2: Deviations of different digital water surface models computed from the green signal only compared to the reference height of test area P06, P14 and R02

(i.e. q1.0) is not a robust estimator but is prone to outliers (i.e. short ranges in this case). Therefore, although the average discrepancies might be the best, still this may cause large (positive) local deviations. Therefore, it might be better to buy to the higher robustness of e.g. the $95 \%$ quantile by accepting a moderate underestimation of the water level. For all tested areas, the $99 \%$ quantile models in $5 \mathrm{~m}$ resolution exhibit average absolute deviations of less than or equal $6 \mathrm{~cm}$ resulting in a final water depth underestimation of ca. $2 \mathrm{~cm}$ which is below the ranging accuracy of the VQ-820-G of $2.5 \mathrm{~cm}$ (Riegl LMS, 2013).

Fig. 6, finally, shows the deviation between the reference height and the different $1 \mathrm{~m}$ quantile models for test areas P06 and P14. As discussed above, the deviations decrease from the lower to the higher quantiles. Furthermore, it can be observed that the increase of approximation precision is almost gradual from q0.5 to $\mathrm{q} 1.0$ for P14. For P06 in contrast, the deviation is $-14 \mathrm{~cm}$ at the $90 \%$ quantile, but there is hardly any gain in precision for the higher quantiles. Again, the reason for this distinct characteristic is the different turbidity of P06 and P14. The vertical point stratification in the more turbid pond 14 is homogeneous within the first $50 \mathrm{~cm}$ water column. For that reason, there is also a high density of points just beneath the true water surface, thus, we obtain a good estimation of the water level even for the small $1 \mathrm{~m}$ raster cell model. To obtain equally good approximation results for P06, a higher aggregation level is necessary (c.f. Tab. 2). 


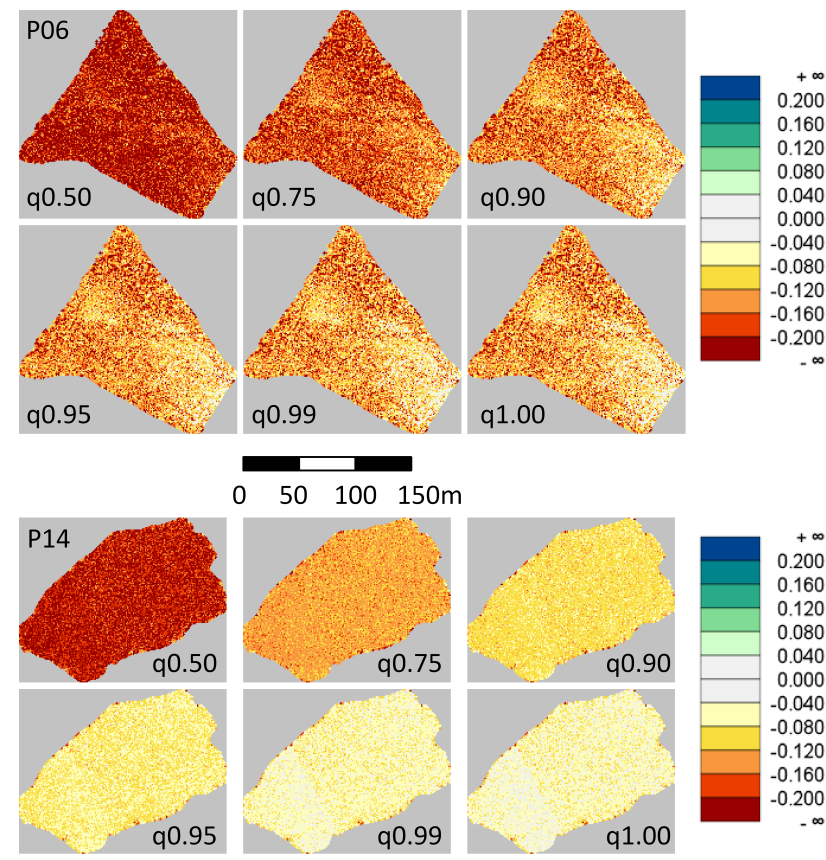

Figure 6: Deviations between reference height and $1 \mathrm{~m}$ digital water surface model grids calculated for different height quantiles; upper: P06; lower: P14

\section{CONCLUSIONS AND OUTLOOK}

In this paper, we have presented the results of an empirical study analyzing the near water surface penetration properties of green laser signal based on a test flight of an alluvial area of the River Pielach (Neubacher Au). Two Riegl laser scanners (VQ-580, $\lambda=1064 \mathrm{~nm}$ and VQ-820-G, $\lambda=532 \mathrm{~nm}$ ) were operated simultaneously to acquire topographic and bathymetric data. 14 still standing ponds and 5 river sections were analyzed. The water levels of the test areas could be extracted with a precision in the range of $2 \mathrm{~cm}$ from the NIR echoes (VQ-580) and served as reference for the comparison with the green returns which were extracted within a $50 \mathrm{~cm}$ band beneath the water surface. The analysis showed: (i) the green signal penetrates $10-25 \mathrm{~cm}$ into the water column (median), (ii) the near water surface penetration depth depends on the water clarity and the mean depth is higher for turbid water, (iii) the overall point density of the green near water surface returns together with their vertical stratification is an indicator for turbidity, (iv) it is possible to approximate the reference water surface level using green near water surface returns only via statistical analysis. For the tested areas it has turned out that robust results can be achieved by calculating the $95-99 \%$ quantile based on $5-10 \mathrm{~m}$ raster cells. The remaining underestimation of the water surface height is in the range of $3-6 \mathrm{~cm}$ resulting in a water depth error of $1-2 \mathrm{~cm}$. As these values are below the ranging accuracy of the employed topo-bathymetric scanner, the feasibility of deriving water surface models from the green signal only for range and refraction correction of water column and water bottom returns was quantitatively verified.

Another major finding of the article was the hint of a connection between geometric properties of the near water surface returns and water turbidity. The assumption of such a causality resulted from relating the results of the statistical analysis visually to the point cloud and/or orthophoto. However, more evidence in the sense of ground truth data and expert knowledge is required for better understanding the acquired point cloud (as the result of the data acquisition process) or even establishing potential correction models. This requires an interdisciplinary cooperation of experts in geomatics and hydrology which is already established within the Austrian Research Promotion Agency (FFG) project "Airborne Alpine HydroMapping - from research to practice (AAHM-R2P)"

\section{ACKNOWLEDGEMENTS}

Gottfried Mandlburger was partly supported by the Austrian Research Promotion Agency (FFG) project AAHM-R2P. Norbert Pfeifer and Gottfried Mandlburger were partly supported by IAPPFP7-Marie Curie project ChangeHabitats2.

\section{REFERENCES}

Guenther, G. C., 1985. Airborne laser hydrography: System design and performance factors. Technical Report ADA488936, National oceanic and atmospheric administration (NOAA).

Guenther, G. C., Cunningham, A., Laroque, P. E. and Reid, D. J., 2000. Meeting the accuracy challenge in airborne lidar bathymetry. In: Proceedings of the 20th EARSeL Symposium: Workshop on Lidar Remote Sensing of Land and Sea, Dresden, Germany.

Guenther, G. C., LaRocque, P. E. and Lillycrop, W. J., 1994. Multiple surface channels in scanning hydrographic operational airborne lidar survey (shoals) airborne lidar. In: Proc. SPIE Vol 2258, Ocean Optics XII, Jules S. Jaffe; Ed., pp. 422-430.

Höfle, B., Vetter, M., Pfeifer, N., Mandlburger, G. and Stötter, J., 2009. Water surface mapping from airborne laser scanning using signal intensity and elevation data. Earth Surface Processes and Landforms 34(12), pp. 1635-1649.

Laroque, P. E. and West, G. R., 1999. Airborne laser hydrography: An introduction. In: Proceedings of the ROPME/PERSGA/IHB Workshop on Hydrographic Activities in the ROPME Sea Area and Red Sea, Kuwait City.

Mandlburger, G., Otepka, J., Karel, W., Wagner, W. and Pfeifer, N., 2009. Orientation and processing of airborne laser scanning data (opals) - concept and first results of a comprehensive als software. In: International Archives of the Photogrammetry, Remote Sensing and Spatial Information Sciences38 (Part 3/W8), Paris, France, pp. 55-60.

Mandlburger, G., Pfennigbauer, M., Steinbacher, F. and Pfeifer, N., 2011. Airborne hydrographic lidar mapping - potential of a new technique for capturing shallow water bodies. In: Proceedings of ModSim'11, New Zealand.

Melcher, A. H. and Schmutz, S., 2010. The importance of structural features for spawning habitat of nase chondrostoma nasus (1.) and barbel barbus barbus (1.) in a pre-alpine river. River Systems 19(1), pp. 33-42.

Pfennigbauer, M., Ullrich, A., Steinbacher, F. and Aufleger, M., 2011. High-resolution hydrographic airborne laser scanner for surveying inland waters and shallow coastal zones. In: Proceedings of SPIE 8037, 8037-5, Orlando, Florida, USA.

Ressl, C., Mandlburger, G. and Pfeifer, N., 2009. Investigating adjustment of Airborne Laser Scanning strips without usage of GNSS/IMU trajectory data. In: International Archives of the Photogrammetry, Remote Sensing and Spatial Information Sciences 38 (Part 3/W8), Paris, FRANCE, pp. 195-200.

Riegl LMS, 2013. www.riegl.com. Homepage of the company RIEGL Laser Measurement Systems GmbH, accessed: June 2013.

Steinbacher, F. and Pfennigbauer, M., 2010. Airborne Hydromapping - Area-wide surveying of shallow water areas. In: Proceedings of the 38th ISPRS Congress, Calgary, Canada. 